\title{
A single amino-acid substitution toggles chloride dependence of the alpha-amylase paralog amyrel in Drosophila melanogaster and Drosophila virilis species
}

\author{
Gaëlle Claisse $^{\text {a, b }}$, Georges Feller ${ }^{c}$, Magalie Bonneau ${ }^{\text {a, b }}$, Jean-Luc Da Lage a, b, * \\ ${ }^{a}$ UMR 9191 Evolution, Génomes, Comportement et Ecologie, CNRS, F-91198 Gif-sur-Yvette, France \\ ${ }^{\mathrm{b}}$ Univ. Paris-Sud, F-91405 Orsay Cedex, France \\ ${ }^{c}$ Laboratory of Biochemistry, Center for Protein Engineering, University of Liège, B-4000 Liège-Sart Tilman, Belgium
}

\section{A R T I C L E I N F O}

\section{Article history:}

Received 19 October 2015

Received in revised form

1 June 2016

Accepted 10 June 2016

Available online 14 June 2016

\section{Keywords:}

$\alpha$-Amylase

Protein evolution

Drosophila

Chloride-dependent enzyme

Digestive enzyme

\begin{abstract}
A B S T R A C T
In animals, most $\alpha$-amylases are chloride-dependent enzymes. A chloride ion is required for allosteric activation and is coordinated by one asparagine and two arginine side chains. Whereas the asparagine and one arginine are strictly conserved, the main chloride binding arginine is replaced by a glutamine in some rare instances, resulting in the loss of chloride binding and activation. Amyrel is a distant paralogue of $\alpha$-amylase in Diptera, which was not characterized biochemically to date. Amyrel shows both substitutions depending on the species. In Drosophila melanogaster, an arginine is present in the sequence but in Drosophila virilis, a glutamine occurs at this position. We have investigated basic enzymological parameters and the dependence to chloride of Amyrel of both species, produced in yeast, and in mutants substituting arginine to glutamine or glutamine to arginine. We found that the amylolytic activity of Amyrel is about thirty times weaker than the classical Drosophila $\alpha$-amylase, and that the substitution of the arginine by a glutamine in $D$. melanogaster suppressed the chloride-dependence but was detrimental to activity. In contrast, changing the glutamine into an arginine rendered $D$. virilis Amyrel chloridedependent, and interestingly, significantly increased its catalytic efficiency. These results show that the chloride ion is not mandatory for Amyrel but stimulates the reaction rate. The possible phylogenetic origin of the arginine/glutamine substitution is also discussed.
\end{abstract}

() 2016 Elsevier Ltd. All rights reserved.

\section{Introduction}

$\alpha$-amylases ( $\alpha$-1,4-glucan-4-glucanohydrolases) constitute the first line in nutrition and digestion processes, as they break down $\alpha-$ 1,4-glycosidic bonds found in starch and related carbohydrates into smaller saccharides. These enzymes are widespread in bacteria, plants, fungi, animals (Janeček, 1994; Stam et al., 2006), and often form multigene families (e.g. Da Lage et al., 2002), generally from intragenomic duplications, but also through lateral gene transfer (Da Lage et al., 2013; Da Lage et al., 2007a).

$\alpha$-amylases of bilaterian animals are thought to have originated by transfer from a proteobacterium, and to have replaced the

Abbreviations used: AmyD, $\alpha$-amylase Amy from Drosophila melanogaster; melrel, Amyrel from D. melanogaster; Virrel, Amyrel from Drosophila virilis.

* Corresponding author. UMR 9191 Evolution, Génomes, Comportement et Ecologie, CNRS, F-91198 Gif-sur-Yvette, France.

E-mail address: jean-luc.da-lage@egce.cnrs-gif.fr (J.-L. Da Lage). former, fungal-like amylase (Da Lage et al., 2007a). Interestingly, whereas most bacterial $\alpha$-amylases do not depend on chloride to perform catalysis, most animal $\alpha$-amylases require a chloride ion to be activated (D'Amico et al., 2000; Levitzki and Steer, 1974; Maurus et al., 2005; Numao et al., 2002; Qian et al., 2005). D'Amico et al. (2000) classified these enzymes as either chloride-independent (Cl-independent) or chloride-dependent ( $\mathrm{Cl}$-dependent). In $\mathrm{Cl}$ dependent enzymes, the chloride anion acts as an allosteric activator (Levitzki and Steer, 1974) that shifts the pKa of the general acid catalyst E233 towards a protonated state (Feller et al., 1996). Furthermore, chloride seems to polarize the catalytic water molecule (Aghajari et al., 2002) and to place catalytically important amino acids in the proper orientation for activity. In human pancreatic $\alpha$-amylase HPA, the chloride ion orients the side chain of the active site residue E233 to optimize the catalytic process (Maurus et al., 2005). In addition, chloride binding increases the affinity of $\alpha$-amylase to bind a calcium ion, which stabilizes the structure (Levitzki and Steer, 1974). Three residues are involved in 
chloride binding: two arginines (R195 and R337) and one asparagine (N298). Numao et al. (2002) and Maurus et al. (2005) have investigated the role of chloride-binding through a structurefunction mutagenesis approach. The mutation R195A severely affects chloride binding, but does not disturb the structure. Rather, it shifts the E233 residue towards the newly opened space within the active site region, decreasing drastically the $k_{\text {cat }}$ value (450- fold). The mutated residue N298S significantly reduces, but does not abolish affinity for chloride ion. Regarding the third chloride binding residue R337, in the absence of chloride, a salt bridge is formed between the positive charge of the arginine and the negative charge of E233. The chloride ion neutralizes the positive charge and disrupts the E233-R337 ion pair, releasing the glutamic acid side chain into the active site. The mutant $\mathrm{R} 337 \mathrm{Q}$ retains full activity, but becomes $\mathrm{Cl}$-independent. Since the glutamine is not charged, no salt bridge is formed, and then E233 is not displaced from its correct orientation. R337 seems to have an essential role in chloride binding only, contrary to the other two residues, in which mutations are detrimental to kinetics parameters. Accordingly, R195 and N298 are strictly conserved in animals, probably because they are involved in other crucial interactions, notably with the catalytic residues, but also with the substrate (Maurus et al., 2005).

In contrast, R337 is sometimes replaced by another basic amino acid, lysine (e.g. in the beetle Ips typographus, GenBank accession ADQ54210). This replacement does not suppress chloride binding (D'Amico et al., 2000) because lysine is also positively charged. However, rarely but consistently, the basic residue R or K337 is replaced by a glutamine in some animal groups, and thus chloride binding should be abolished. The occurrence of a glutamine is the case in all lepidopteran $\alpha$-amylases known to date. In the moth Ephestia kuehniella, activity of EkAmy3 (ACL14798) has been shown to be $\mathrm{Cl}$-independent (Pytelková et al., 2009). These observations prompted us to focus on this residue and on chloride-dependence because of the peculiar situation encountered in Diptera. True flies (Muscomorpha), possess an $\alpha$-amylase paralogue named Amyrel, first described in Drosophila (Da Lage et al., 1998; Maczkowiak and Da Lage, 2006). It is divergent from Amy by as much as 40\% (Fig. 1). It has been very rarely reported to be pseudogenized (Yassin et al., 2008; Legrand et al., 2009) but its function and its biological significance are still unclear. Numerous Amyrel sequences were obtained in the genus Drosophila and other genera or families (Da Lage et al., 2007a; Maczkowiak and Da Lage, 2006). Hereafter, we will use the Drosophila melanogaster Amyrel paralogue numbering (see Table 1 for correspondence with mammal numbering). As in other $\alpha$-amylases, in all the Amyrel sequences available the residues forming the catalytic triad are conserved; three of the four residues that bind the essential calcium ion are conserved; only the calciumbinding R147 of Amy is substituted by a glutamine (Q149) in Amyrel (Maczkowiak and Da Lage, 2006), although coordination is made via the main chain carbonyl. Regarding our present focus, the three chloride-binding residues R186, N288 and R323 (R184, N286, R325 in Amy, respectively) are generally conserved too. But surprisingly, in Drosophila virilis and in all the subgenus Drosophila to which $D$. virilis belongs (several hundreds of species), a glutamine replaces the usual arginine ligand at position 323 , which supposedly impairs chloride fixation (Fig. 1). Amyrel of $D$. virilis therefore constitutes a natural "mutant" to study the impact of chloride on Amyrel activity. In regard of this R323Q natural substitution, we hypothesized that Amyrel of $D$. virilis cannot bind a chloride ion whereas Amyrel of D. melanogaster keeps this ability through the conserved arginine, and therefore may be activated by chloride. Indeed, if this is confirmed, it raises a puzzling question about why, evolutionarily speaking, some drosophila species would have $\mathrm{Cl}$-independent Amyrels while others would have $\mathrm{Cl}$-dependent Amyrels.

In Drosophila melanogaster and several other Drosophila species, including D. virilis (Prigent et al., 1998), biochemical properties of the classical Amy enzyme have been studied on crude or purified tissue extracts (Doane, 1969; Hoorn and Scharloo, 1978; Milanovic and Andjelkovic, 1992; Shibata and Yamazaki, 1994) or on recombinant, purified amylases produced either in bacteria (Cipolla et al., 2012) or yeast (Commin et al., 2013). However, Amyrel had not been biochemically characterized to date. Here we investigated for the first time the activity parameters of Amyrel in D. melanogaster and $D$. virilis, compared to the $\alpha$-amylase AmyD from D. melanogaster, all of them produced in yeast. Because of the striking arginine/glutamine substitution, we focused our study on the role of chloride in activation of Amyrel. We have engineered reciprocal Amyrel mutants, i.e. the $D$. melanogaster $\mathrm{R} 323 \mathrm{Q}$ mutant, and the $D$. virilis Q323R mutant, in order to assess the effects of these changes, in regard to chloride binding and activation, and their consequences regarding activity parameters.

\section{Materials and methods}

\subsection{Expression, site-directed mutagenesis and preparation of recombinant proteins}

The amino acid sequences of $\alpha$-amylase and Amyrel paralogues used for this study were the following: AmyD from $D$. melanogaster (BAB32511, corresponding to the electrophoretic class Amy1 (Araki et al., 2001)), Amyrel from D. melanogaster, hereafter named melrel (AAF57971) and Amyrel from D. virilis, hereafter named virrel (AAF61427). Fig. 1 shows an alignment of these sequences, along with the pig ( $S$. scrofa) pancreatic $\alpha$-amylase sequence (PPA, AAF02828).

The relevant nucleotide sequences were cloned into the PCR2.1 plasmid vector (Invitrogen) with the native signal sequence (for AmyD and Amyrel from D. melanogaster) or in frame with the yeast alpha-peptide (for Amyrel from D. virilis). Both strategies performed equally well for secretion by Pichia pastoris. The Amyrel intron was removed from the genes by inverse PCR, then the desired mutations (Arg > Gln or Gln > Arg) were created by inverse PCR using primers bearing the relevant substitutions. The modified or native genes were ligated to the expression vector pPIC9K (Invitrogen), in frame with the alpha-peptide of yeast (Amyrel from D. virilis), or pPIC3.5 K with their own signal peptide (AmyD and Amyrel from D. melanogaster). After amplification in Escherichia coli DH5 $\alpha$ and control by sequencing, the plasmids were linearized and transferred by electroporation into the Pichia pastoris strains GS115 and KM71. The Multi-copy Pichia expression kit (Invitrogen) was used according to the manufacturer's instructions. $P$. pastoris is a methylotrophic yeast and the gene of interest is under control of the methanol-inducible $A O X 1$ promoter. The recombinant strains were tested for expression in BMMY broth, containing $0.5 \%$ methanol, at $28{ }^{\circ} \mathrm{C}$ with vigorous shaking, for 2 days. Supernatants were assayed for activity and quality on starch-agarose plate and SDSPAGE. Recombinant proteins were purified as described in Commin et al. (2013) using glycogen precipitation in alcoholic conditions. The proteins were dialyzed against $20 \mathrm{mM}$ Hepes, $20 \mathrm{mM} \mathrm{NaCl}, 1 \mathrm{mM} \mathrm{CaCl}$, pH 7.5. Then, for the specific purpose of chloride removal, proteins were extensively dialyzed against Hepes- $\mathrm{NaOH}$ or Mes-NaOH buffers without $\mathrm{NaCl}$ or $\mathrm{CaCl}_{2}$. Solutions of AmyD and Amyrel were stored in Hepes buffer ( $\mathrm{pH} 7.5$ ) or in Mes buffer ( $\mathrm{pH} 6$ ), respectively, at $-20{ }^{\circ} \mathrm{C}$, with or without $\mathrm{NaCl}$ according to the experimental requirements. The molecular weight of the native and mutated recombinant enzymes were calculated with the ProtParam tool available at the ExPASy molecular biology server (www.expasy.org). The following masses were used for calculations: AmyD, 51,899 Da; melrel, 53,468 Da; melrel R323Q, 53,440 Da; virrel, 53,785 Da and virrel Q323R, 53,813 Da. 


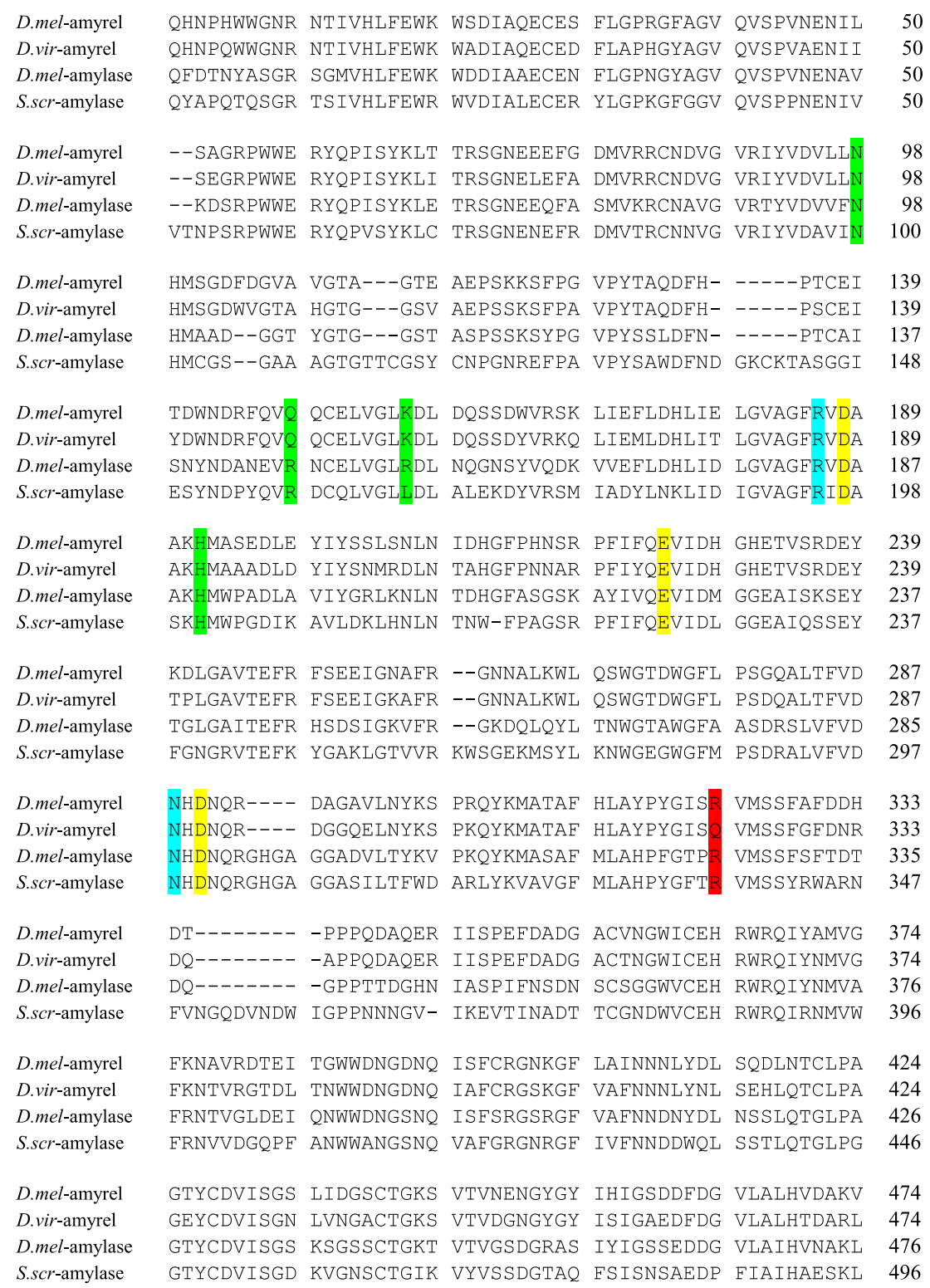

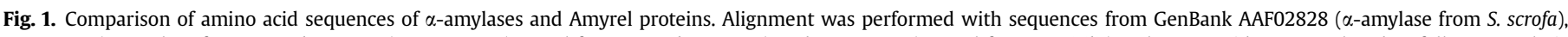

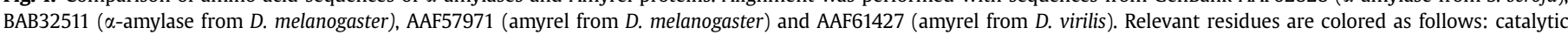

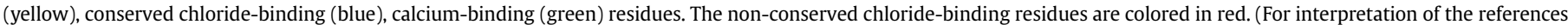
to colour in this figure legend, the reader is referred to the web version of this article.)

Table 1

Correspondence of amino acid positions between alpha-amylases and Amyrel paralogues in species considered in this study.

\begin{tabular}{|c|c|c|c|c|}
\hline Species & Name & Active site & Chloride binding & Calcium binding \\
\hline H. sapiens & HPA & D197, E233, D300 & R195, N298, R337 & N100, R158, D167, H201 \\
\hline S. scrofa & PPA & D197, E233, D300 & R195, N298, R337 & N100, R158, D167, H201 \\
\hline P. haloplanktis & AHA & D174, E200, D264 & R172, N262, K300 & N88, Q135, D144, H178 \\
\hline D. melanogaster & Amy & D186, E223, D288 & R184, N286, R325 & N98, R147, D156, H190 \\
\hline D. melanogaster & Amyrel & D188, E225, D290 & R186, N288, R323 & N98, Q149, D158, H192 \\
\hline D. virilis & Amyrel & D188, E225, D290 & R186, N288, Q323 & N98, Q149, D158, H192 \\
\hline E. kuehniella & EkAmy3 & D193, E230, D295 & R191, N293, Q331 & N100, R154, D163, H197 \\
\hline A. oryzae & TAKA & D206, E230, D297 & R204, N295, I326 & N121, E162, D175, H210 \\
\hline
\end{tabular}

Concentrations of the purified preparations were determined using 4-12\% Bis-Tris SDS-PAGE (Invitrogen) with a range of BSA mass standards. The protein bands were stained by Coomassie blue and the quantification of each enzyme was carried out with an Odyssey FC imager system (Li-Cor).

\subsection{AmyD and amyrel activities}

The $\alpha$-amylase activity of the recombinant enzymes was first determined by the diagnostic kit Infinity Amylase (Thermo Scientific) using the synthetic substrate p-nitrophenyl- $\alpha-D$ - 
maltoheptaoside-4,6-O-ethylidene (Et-G7-pNP or EPS), the hydrolysis of which, coupled with an alpha-glucosidase, releases free pnitrophenol. Enzymatic activity was calculated on the basis of an absorption coefficient for p-nitrophenoscide ion of $8980 \mathrm{M}^{-1} \mathrm{~cm}^{-1}$ at $405 \mathrm{~nm}$. Assays were performed at $25^{\circ} \mathrm{C}$ in the buffer supplied, which contains $50 \mathrm{mM} \mathrm{NaCl}$, at $\mathrm{pH} 7.0$.

After this exploratory step, enzyme activities were measured in triplicates using the dinitrosalicyclic (DNS) method (Bernfeld, 1955) that reveals the reducing ends released by digestion of soluble starch (Merck $n^{\circ}$ 1252). The optimum $\mathrm{pH}$ conditions for enzyme activities were determined at $25^{\circ} \mathrm{C}$ in the $\mathrm{pH}$ range from 3 to 10 using $10 \mathrm{~g} / \mathrm{l}$ soluble starch as substrate. The incubation time was set between 5 and $30 \mathrm{mn}$ depending on the activity and the dilution of the enzymes. The buffer contained $20 \mathrm{mM}$ sodium acetate $(\mathrm{pH}$ 3-5.5), Mes (pH 6-6.5), Hepes (7-7.5), or Tris ( $\mathrm{pH} \mathrm{8-10),} 20 \mathrm{mM}$ $\mathrm{NaCl}, 1 \mathrm{mM} \mathrm{CaCl} 2$. The optimum temperature conditions were assessed in the range from $20{ }^{\circ} \mathrm{C}$ to $70{ }^{\circ} \mathrm{C}$ with $10 \mathrm{~g} / \mathrm{l}$ starch as substrate in $20 \mathrm{mM}$ Hepes, $20 \mathrm{mM} \mathrm{NaCl}, 1 \mathrm{mM} \mathrm{CaCl}_{2}$, pH 7.5 for AmyD, and $20 \mathrm{mM}$ Mes, $20 \mathrm{mM} \mathrm{NaCl}, 1 \mathrm{mM} \mathrm{CaCl} 2, \mathrm{pH} 6.0$ for Amyrel. In this case, the incubation time was $5 \mathrm{mn}$.

The kinetic parameters $\left(K_{m}\right.$ and $k_{\text {cat }}$ ) of enzymes were determined at $25{ }^{\circ} \mathrm{C}$ with starch concentrations ranging from 0 to $30 \mathrm{~g} / \mathrm{l}$ in $20 \mathrm{mM}$ Hepes, $20 \mathrm{mM} \mathrm{NaCl}, 1 \mathrm{mM} \mathrm{CaCl}_{2}$, pH 7.5 for AmyD and in $20 \mathrm{mM}$ Mes, $20 \mathrm{mM} \mathrm{NaCl}, 1 \mathrm{mM} \mathrm{CaCl}_{2}$, pH 6.0 for native or mutated Amyrel. Saturation curves were fitted by a nonlinear regression according to the Michaelis-Menten equation.

\subsection{Effect of chloride on enzyme activity}

In order to determine the effect of substituting the arginine involved in the chloride binding site, activities of native or mutated Amyrel were tested at $25^{\circ} \mathrm{C}$ in a concentration range of $\mathrm{NaCl}$, using chloride-free enzyme samples, with $10 \mathrm{~g} / \mathrm{l}$ starch as substrate in $20 \mathrm{mM}$ Mes, pH 6.0. AmyD was assayed, as a control, in $20 \mathrm{mM}$ Hepes, $\mathrm{pH}$ 7.5. The $\mathrm{pH}$ of buffers was adjusted with $\mathrm{NaOH}$. Chloride dissociation constant $K_{\mathrm{d}}$ was determined by nonlinear regression on the binding isotherm using the modified Hill equation:

$v-v_{0}=k_{c a t}\left[\mathrm{Cl}^{-}\right] / \mathrm{K}_{d}+\left[\mathrm{Cl}^{-}\right]$

where $v_{0}$ is the activity of the chloride-free enzyme and assuming a Hill coefficient of 1 .

\section{Results}

The five investigated enzymes, AmyD (the $\alpha$-amylase from D. melanogaster), melrel (the Amyrel paralogue from D. melanogaster), virrel (the Amyrel paralogue from $D$. virilis), the mutants melrel R323Q and virrel Q323R, were produced in the culture supernatant of the yeast $P$. pastoris and were purified by a combination of ammonium sulfate precipitation, solubilization and glycogen precipitation in $40 \%$ cold ethanol. The enzyme preparations appeared homogenous on SDS-PAGE.

The standard assay using ethylidene-G7-pNP (EPS) as substrate at $25{ }^{\circ} \mathrm{C}$ (Suppl. Fig. 1 ), which is specific to $\alpha$-amylases, retrieved low apparent amylolytic activity values for the wildtype Amyrel paralogues, about 30 times lower than AmyD (ca. $6.8 \mathrm{~s}^{-1}$ for melrel and $7.6 \mathrm{~s}^{-1}$ for virrel, compared to ca. $232 \mathrm{~s}^{-1}$ for AmyD). Furthermore, the R323Q mutant of melrel had a strongly decreased $k_{\text {cat }}$ of $2.0 \mathrm{~s}^{-1}$ whereas the Q323R mutant of virrel had an increased $k_{\text {cat }}$ of $28.1 \mathrm{~s}^{-1}$. These results indicate that the amylolytic activity of Amyrel is quite low, whatever the species.

\subsection{Effects of $\mathrm{pH}$ and temperature}

The curves of $\mathrm{pH}$ and temperature dependence of activity are shown in Fig. 2. For AmyD produced in yeast, our results $\left(\mathrm{pH}_{\mathrm{opt}} 7.5\right.$ and $\mathrm{T}_{\text {opt }} 50-55^{\circ} \mathrm{C}$, Fig. 2, left) are in agreement with previously published values for the optimum $\mathrm{pH}(7.2-7.4)$ and the optimum temperature $\left(54-55^{\circ} \mathrm{C}\right.$ ) of AmyD produced in E. coli (Cipolla et al., 2012). In the case of Amyrel paralogues, the optimum was around $\mathrm{pH} \mathrm{6-6.5} \mathrm{for} \mathrm{both} \mathrm{melrel} \mathrm{and} \mathrm{virrel} \mathrm{and} \mathrm{also} \mathrm{for} \mathrm{their} \mathrm{mutants,}$ (Fig. 2, upper panel). The optimum temperature was around $55^{\circ} \mathrm{C}$ for all Amyrel enzymes (Fig. 2, lower panel). The mutations introduced in the chloride binding site (R323Q or Q323R) do not affect these parameters, whereas activity at extreme $\mathrm{pH}$ values is modified.

\subsection{Kinetic parameters for starch hydrolysis}

With starch as substrate, the results were parallel to the values obtained with EPS. The native melrel and virrel showed $k_{\text {cat }}$ values of $12.9 \mathrm{~s}^{-1}$ and $21.2 \mathrm{~s}^{-1}$, respectively (Table 2). In contrast, the mutant melrel R323Q displayed a $k_{\text {cat }}$ lowered to $3.6 \mathrm{~s}^{-1}$, showing a detrimental effect of the mutation (Fig. 3, middle), but interestingly, the reciprocal mutation Q323R in virrel enhanced the $k_{\text {cat }}$ up to $42.3 \mathrm{~s}^{-1}$, i.e. twice the value of the wildtype (Fig. 3 , right). As with the EPS synthetic substrate, the kinetic constants of both nonmutated Amyrel paralogues were about thirty times lower than that of AmyD, the $k_{\text {cat }}$ of which was $598 \mathrm{~s}^{-1}$.

The $K_{m}$ values for starch hydrolysis were similar for all native and mutated Amyrel (ca. $0.6 \mathrm{~g} / \mathrm{l}$, Table 2). These values indicated affinities for starch about three times higher than AmyD (1.9 g/l). Given the similar values of $K_{m}$ of the four Amyrel enzymes, the catalytic efficiencies $k_{\text {cat }} / K_{m}$ mainly reflect the differences in $k_{\text {cat }}$.

\subsection{Effect of chloride on amylolytic activity}

Like most animal $\alpha$-amylases (D'Amico et al., 2000), AmyD is activated by chloride (Cipolla et al., 2012). Our test value on AmyD produced in P. pastoris $\left(K_{\mathrm{d}}=0.28 \mathrm{mM}\right.$, Table 2$)$ is in agreement with the value $(0.22 \mathrm{mM})$ reported by Cipolla et al. (2012) for the same enzyme produced in $E$. coli. The value of $K_{\mathrm{d}}$ indicates a moderate affinity for the chloride ion.

As expected from the occurrence of the three chloride-binding residues in its sequence, melrel was also activated by chloride (Fig. 4, middle, and Table 2), but with a four times higher affinity at $25^{\circ} \mathrm{C}\left(K_{\mathrm{d}}=67 \mu \mathrm{M}\right)$. The fact that in the chloride-free buffer, melrel activity remained about $20 \%$ below its full activity level (Table 2 ) indicates that the allosteric chloride ion is tightly bound to the enzyme and is inefficiently removed by dialysis. The mutation R323Q in melrel abolished chloride activation (Fig. 4, middle). This demonstrates that arginine at position 323 in melrel confers chloride binding, which in turn increases the enzyme catalytic activity.

In $D$. virilis, the activity of the Amyrel paralogue virrel was unaffected by $\mathrm{NaCl}$ (Fig. 4, right). Accordingly, virrel, which is devoid of the chloride-binding arginine, is natively chloride-independent. Interestingly, the substitution Q323R in virrel not only rescued the binding of the chloride ion with high affinity, but also notably increased the enzymatic activity up to $42 \mathrm{~s}^{-1}$ in the presence of $\mathrm{NaCl}$.

\section{Discussion}

We have shown in the present work that Amyrel enzymes display an amylolytic activity and that they can be either $\mathrm{Cl}$ dependent or $\mathrm{Cl}$-independent depending on the species. 

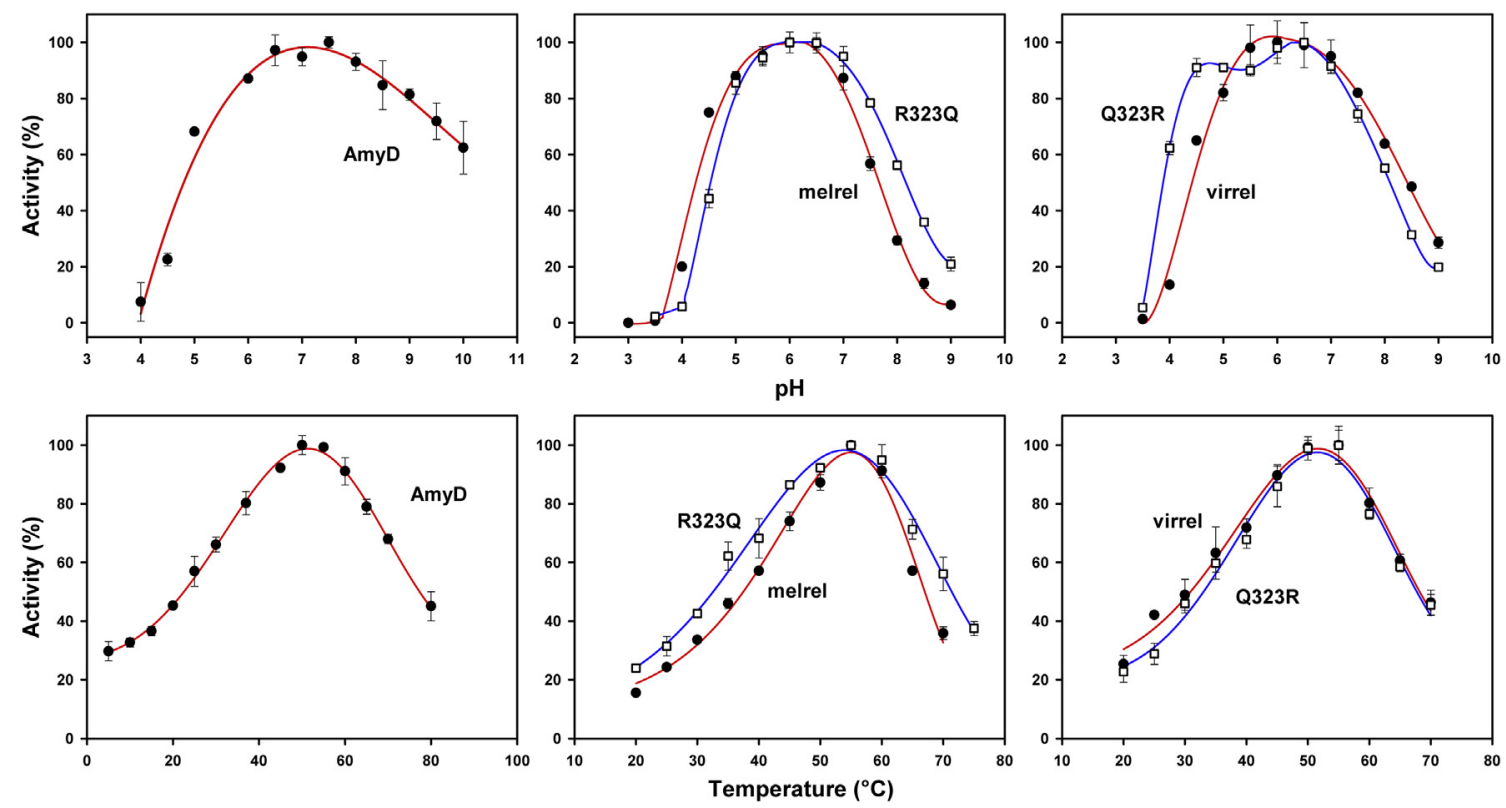

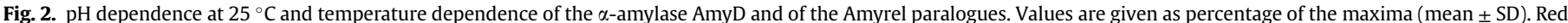

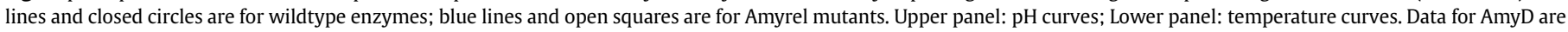
adapted from Commin et al., 2013. (For interpretation of the references to colour in this figure legend, the reader is referred to the web version of this article.)

Table 2

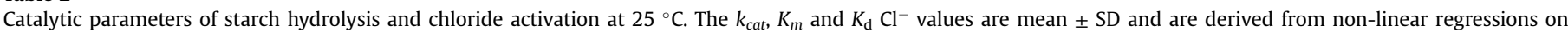
Michaelis-Menten or Hill equations on data shown in Figs. 3 and 4 n.a. not applicable.

\begin{tabular}{|c|c|c|c|c|c|}
\hline Enzyme & $k_{\text {cat }} \mathrm{s}^{-1}$ & $K_{m} \mathrm{~g} / \mathrm{l}$ & $k_{\text {cat }} / K_{m} \mathrm{~s}^{-1} \mathrm{~g}^{-1} \mathrm{l}$ & Cl-free activity $\% k_{\text {cat }}$ & $K_{\mathrm{d}} \mathrm{Cl}^{-} \mu \mathrm{M}$ \\
\hline AmyD & $598 \pm 16$ & $1.9 \pm 0.3$ & 315 & 23 & $279 \pm 20$ \\
\hline melrel & $12.9 \pm 0.5$ & $0.7 \pm 0.1$ & 18 & 80 & $67 \pm 13$ \\
\hline melrel R323Q & $3.6 \pm 0.1$ & $0.6 \pm 0.1$ & 6 & 100 & n.a. \\
\hline virrel & $21.2 \pm 0.8$ & $0.6 \pm 0.1$ & 35 & 100 & n.a. \\
\hline virrel Q323R & $42.3 \pm 1.5$ & $0.7 \pm 0.1$ & 60 & 33 & $99 \pm 5$ \\
\hline
\end{tabular}
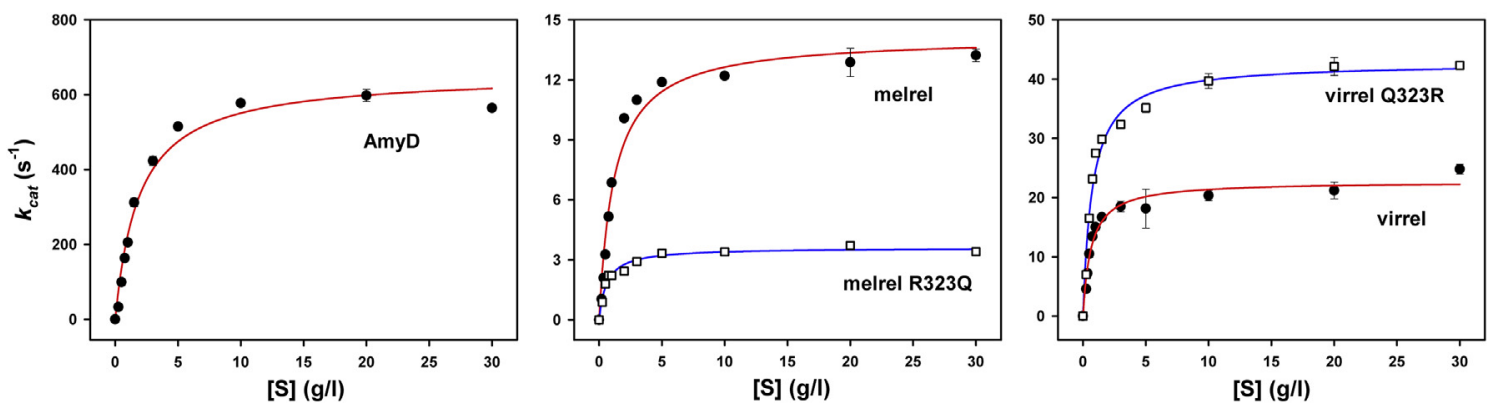

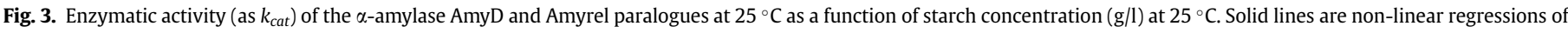

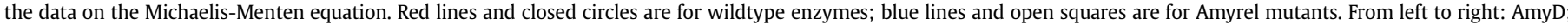
melrel and melrelR323Q; virrel and virrel Q323R. (For interpretation of the references to colour in this figure legend, the reader is referred to the web version of this article.)

\subsection{R323 enables chloride binding in amyrel}

In melrel, the Amyrel of $D$. melanogaster, R323 is necessary for chloride-binding. The introduced R323Q mutation results in the loss of chloride activation with, moreover, a 3-fold decrease of activity compared to the native form. In contrast, the native Amyrel of $D$. virilis virrel, which displays a glutamine at position 323 , is $\mathrm{Cl}$ independent but the engineered Q323R mutation restores a strong chloride activation, with an improved catalytic activity $\left(k_{\text {cat }}\right)$ and efficiency $\left(k_{\text {cat }} / K_{m}\right)$ (Table 2 ). It is worth mentioning that previous attempts to engineer chloride binding and activation in $\mathrm{Cl}$ independent $\alpha$-amylase have been unsuccessful (Maurus et al., 2005). These results confirm our assumptions on Cl-dependence in Amyrel and are consistent with previous works carried out on the homologous chloride-binding residue of other $\mathrm{Cl}$-dependent animal $\alpha$-amylases. For example in AHA from Pseudoalteromonas haloplanktis, a bacterium with an animal-like $\alpha$-amylase, the corresponding mutated chloride-binding residue showed similar results, although with a higher decrease of catalytic activity (8-fold for the AHA K300Q mutant) (Aghajari et al., 2002; Feller et al., 

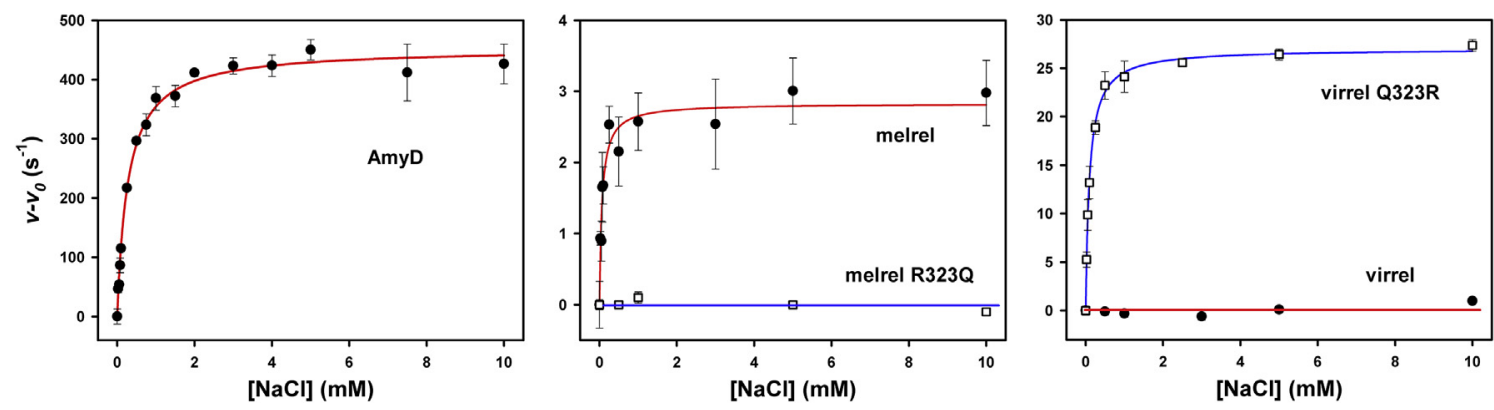

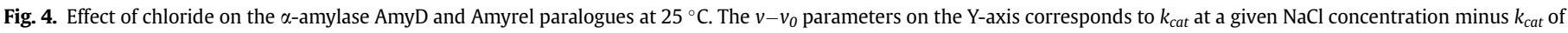

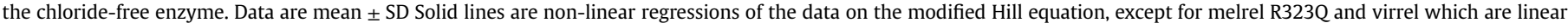

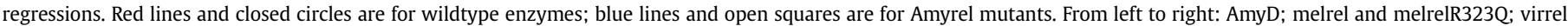
and virrel Q323R. (For interpretation of the references to colour in this figure legend, the reader is referred to the web version of this article.)

1996). On the other hand, the mutant HPA R337Q showed no difference in activity while it became $\mathrm{Cl}$-independent (Numao et al., 2002).

Maurus et al. (2005) have shown that in absence of the chloride ion there is a direct interaction between R337 and E233 which disrupts the normal orientation of this catalytic residue. The chloride ion prevents the formation of a salt bridge between E233 and the side chain of R337, and in addition, it maintains E233 protonated at neutral pH (Feller et al., 1996) and polarizes the catalytic water molecule (Aghajari et al., 2002), favoring activity at neutral $\mathrm{pH}$. The $\mathrm{Cl}$-independent amylases would not need a chloride ion because the glutamine residue at position 337 does not interact with E233, which is the case with basic amino acids of the $\mathrm{Cl}$-dependent amylases. In Cl-independent amylases, E233 maintains a correct position due to substitution of a non-basic residue at position 337. Indeed, structural studies have shown that the conformation of the active site of the HPA R337Q mutant is likely in the same position as the native enzyme (Numao et al., 2002).

It should be mentioned here that contrary to suggestions of Maurus et al. (2005), there is no direct relationship between chloride-binding (i.e. Cl-dependent amylases) and the presence of the "flexible loop", a glycine-rich stretch of amino acids located close to the catalytic cleft (André and Tran, 2004; Qian et al., 2005; Ramasubbu et al., 2003). For instance, Amyrel always lacks this loop and may be either $\mathrm{Cl}$-dependent or not. Lepidoptera $\alpha$-amylases do have the loop and are $\mathrm{Cl}$-independent whereas beetle $\alpha$-amylases lack the loop and are $\mathrm{Cl}$-dependent.

\subsection{Chloride ion binds with high affinity to amyrel paralogues}

We have determined the dissociation constant for chloride for the two $\mathrm{Cl}$-dependent Amyrel produced, and have shown that their $K_{\mathrm{d}} \mathrm{Cl}^{-}(67-99 \mu \mathrm{M})$ are lower than those of other animal $\alpha$-amylases: $0.53 \mathrm{mM}$ for HPA (Numao et al., 2002) $0.22 \mathrm{mM}$ for AmyD from D. melanogaster produced in bacteria (Cipolla et al., 2012), 0.29-0.36 mM for PPA (Levitzki and Steer, 1974; Qian et al., 2005). Interestingly, the $K_{\mathrm{d}}$ value of the mutated virrel Q323R $(99 \mu \mathrm{M})$ was of the same order of magnitude than the $K_{\mathrm{d}}$ of the native melrel $(67 \mu \mathrm{M})$, suggesting that the substitution into Q323 occurred during evolution without other perturbations in the chloride binding site environment. This is in sharp contrast with AHA from P. haloplanktis: for this $\mathrm{Cl}$-dependent $\alpha$-amylase, the mutation K300R has strong consequences, decreasing twofold the activity and increasing tenfold the $K_{\mathrm{d}}$ value, possibly because of steric hindrances introduced by the large arginine side chain (Feller et al., 1996).

\subsection{Catalytic activity in absence of bound chloride}

Both $\mathrm{Cl}$-dependent and $\mathrm{Cl}$-independent $\alpha$-amylases coexist in animals. The absence of chloride is a theoretical case, since this ion is ubiquitous in body fluids and in water. Most $\mathrm{Cl}$-dependent $\alpha$ amylases show residual activity in the absence of chloride notwithstanding a substantial drop in activity: 12- to 25-fold for mammals (Levitzki and Steer, 1974; Numao et al., 2002) or 4-fold in D. melanogaster AmyD (Table 2). One cannot exclude that this residual activity originates from the inability to fully remove chloride from buffers, as suggested by the complete loss of activity in $\mathrm{Cl}^{-}$free AHA, which has a weak affinity for the anion (Feller et al., 1996). This could explain why melrel retained appreciable activity after dialysis and assay in a chloride-free environment, with an estimated $10 \mu \mathrm{M}$ chloride contamination in reagents (Feller et al., 1996).

However, when the $\mathrm{Cl}$-dependent $\alpha$-amylases are rendered $\mathrm{Cl}$ independent through arginine to glutamine substitution, the loss of bound chloride may be detrimental to catalytic activity, but does not abolish it completely. Interestingly, the natively $\mathrm{Cl}$-independent virrel paralogue possesses a higher $k_{\text {cat }}$ than melrel (21.2 and $12.9 \mathrm{~s}^{-1}$, respectively, Table 2), while the $\mathrm{Cl}$-independent engineered melrel $\mathrm{R} 323 \mathrm{Q}$ is much less active $\left(3.6 \mathrm{~s}^{-1}\right)$. This suggests that the inability to bind a chloride ion in virrel has been balanced by subtle compensatory amino acid changes to remain active. Moreover, when restoring chloride binding in virrel by the Q323R substitution, the mutant shows a 2 -fold increased activity in the presence of chloride compared to the wildtype, and its $k_{\text {cat }}$ is much higher than the native melrel in the presence of chloride. This also suggest that the above-mentioned compensatory changes in the virrel structure are still beneficial when chloride is allowed to bind close to the active center and contributes to improve the catalytic activity.

\subsection{Chloride-binding does not influence the affinity for starch}

The native virrel and melrel, as well as their mutants, have similar $K_{m}$ values (0.6-0.7 g/l, Table 2), showing higher apparent affinity for starch than the $\alpha$-amylase AmyD. This shows that the ability or unability to bind chloride in Amyrel has no consequence on starch binding. When compared to $\alpha$-amylases from other insects, the Amyrel enzymes have an average apparent affinity for starch: $0.43 \mathrm{~g} / \mathrm{l}$ in the beetle Morimus cinereus (Dojnov et al., 2008); $1.8 \mathrm{~g} / \mathrm{l}$ in Tenebrio molitor (Buonocore et al., 1976); $5.4 \mathrm{~g} / \mathrm{l}$ in the Sunn pest Eurygaster integriceps (Bandani et al., 2009); $1.1 \mathrm{~g} / \mathrm{l}$ in Antheraea myllita (Nagaraju and Abraham, 1995); 0.3-0.6 g/l in Glyphodes pyoalis (Yezdani et al., 2010). The latter two species are Lepidoptera, 
which have Cl-independent amylases (Pytelková et al., 2009).

\subsection{Chloride-binding does not modify $\mathrm{pH}$ optima in amyrel paralogues}

In previous reports, chloride binding to HPA and to AHA switched the optimum pH from acidic to neutral (Feller et al., 1996; Numao et al., 2002). In contrast, the virrel and melrel Amyrel paralogues have similar slightly acidic pH optima (ca. pH 6.0-6.5), whereas the $\alpha$-amylase AmyD has a neutral optimum $\mathrm{pH}$ of 7.5. The mutations introduced in the two Amyrel paralogues do not modify this parameter. For identified $\mathrm{Cl}$-independent $\alpha$-amylases, the catalytic activity is optimal at acidic values e.g. $\mathrm{pH} 5.9$ for Bacillus amyloliquefaciens (BAA) (Welker and Campbell, 1967); $\mathrm{pH} 4.5$ for Aspergillus oryzae (TAKA) (Kariya et al., 2003); pH 5.5 for barley (MacGregor, 1978), with the noticeable exception of Lepidoptera, which show an optimum pH of 8-10 (Abraham et al., 1992; Kotkar et al., 2009; Nagaraju and Abraham, 1995; Pytelková et al., 2009; Valencia-Jiménez et al., 2008; Yezdani et al., 2010). Our results do not support the proposition of Pytelková et al. (2009) that the arginine to glutamine mutation would be adaptive to an alkaline $\mathrm{pH}$. On the other hand, it is possible that the absence of the flexible loop in Amyrel is involved in the acidic optimal pH of these enzymes. Indeed, in a mutant of $D$. melanogaster AmyD in which the flexible loop motif GHGA has been removed, a shift towards acidic optimum pH has been observed (JLDL, unpublished results). Coleoptera also lack this loop and the optimum $\mathrm{pH}$ is known to be acidic (Kluh et al., 2005).

\subsection{Phylogenetic distribution of residue $R 323$}

Chloride binding mediated by R323 (R337 in mammals) can be considered as relatively "recent" in evolution, since it is more or less limited to animals (Brayer et al., 1995; Da Lage et al., 2002). We have previously proposed that animal $\alpha$-amylases originated from a lateral gene transfer from a bacterium, which may have been $\mathrm{Cl}$ dependent (Da Lage et al., 2007a). In bacterial species which have an animal-type $\alpha$-amylase, it is either $\mathrm{Cl}$-independent, or if $\mathrm{Cl}$ dependent, there is most often a lysine instead of an arginine, like in AHA (Suppl. Fig. 2). As far as we know, the only animal-like bacterial $\alpha$-amylase sequenced to date with an arginine at the corresponding position is in Hahella chejuensis (WP_011397928). However, in extant animal (bilaterian) $\alpha$-amylases R323 is obviously ancestral. Most of them have this residue and are believed to be Cl-dependent (D'Amico et al., 2000). The reported exceptions are Lepidoptera (see above), one of the copies of Daphnia pulex (EFX66437) and Amyrel proteins of a group of drosophilids. Indeed, Lepidopteran amylases have been shown experimentally to be $\mathrm{Cl}$ independent (Pytelková et al., 2009), and we have shown here that Amyrel is Cl-independent when Q323 occurs in the sequence. Regarding drosophilids, it is important to remind that classical amylases of all species have an arginine, and that the $\mathrm{R}$ to $\mathrm{Q}$ substitution may concern Amyrel only. In D. virilis, Amy has an arginine and is $\mathrm{Cl}$-dependent, but Amyrel has a glutamine and is $\mathrm{Cl}$ independent. This makes the story physiologically surprising. To point to the puzzling fact that some drosophilids have a $\mathrm{Cl}$ independent Amyrel whereas others are $\mathrm{Cl}$-dependent, although they share similar ecological and physiological conditions, we ought to understand the history of this substitution. However, because the phylogeny among non-Drosophila drosophilids is not firmly established, it is not clear whether the arginine is ancestral or not in Drosophilids, since, in addition to the subgenus Drosophila, more remote species inside the family may have either an arginine or a glutamine (Suppl. Fig. 3). In any case, the current situation required several parallel events, either parallel reversions from glutamine to arginine if glutamine was basal to the drosophilids, or parallel mutations from arginine towards glutamine in the other case. Interestingly, in animals with $\mathrm{Cl}$-independent amylase, it is most often a glutamine that replaces the arginine residue. The reason is not obvious, since although a single $C$ to $T$ mutation is sufficient to change an arginine codon into a glutamine codon, other single non-synonymous substitutions might occur. The amino acid replacing arginine must be non-basic, because of the salt bridge that would be otherwise created; it should not be acidic either, because of the extra negative charge that would disturb the catalytic reaction; it should not be aliphatic, because hydrophobicity would repulse the required catalytic water molecule; it should not be aromatic, since aromatic cycles interact with substrate handling; only polar side chains remain, but asparagine would be too short, and therefore glutamine would be the right candidate. Whenever the $\mathrm{R}$ to $\mathrm{Q}$ substitution occurred, this event must have been accompanied or preceded by other changes that maintained an appropriate activity, since the mere $\mathrm{R}$ to $\mathrm{Q}$ mutation leads to a decrease in activity (evidenced by our mutant melrel $\mathrm{R} 323 \mathrm{Q})$. If $\mathrm{Q}$ was ancestral in Drosophilids, although a reverse mutation towards $\mathrm{R}$ would require the presence of chloride to be advantageous, this would not be an issue since chloride is ubiquitous in animals. One could expect reverse $\mathrm{Q}$ to $\mathrm{R}$ mutations to have occurred in species of the subgenus Drosophila, since in the mutant virrel, it boosted activity, but only if a higher activity would be evolutionarily advantageous. But there is no evidence supporting such a speculation, as we are still ignorant of the real physiological role of Amyrel, and indeed no glutamine to arginine mutation was observed in dozens of species belonging to the subgenus Drosophila (Da Lage et al., 2007b).

\section{Acknowledgments}

This work was funded by the Agence Nationale de la Recherche (ANR-097-PEXT-009) for the project "Adaptanthrop" to GC and JLDL and by the Belgian program of Interuniversity Attraction Poles (iPros P7/44), initiated by the Federal Office for Scientific, Technical and Cultural Affairs, to GF.

\section{Appendix A. Supplementary data}

Supplementary data related to this article can be found at http:// dx.doi.org/10.1016/j.ibmb.2016.06.003.

\section{References}

Abraham, E.G., Nagaraju, J., Datta, R.K., 1992. Biochemical studies of amylases in the silkworm, Bombyx mori L.: comparative analysis in diapausing and nondiapausing strains. Insect Biochem. Mol. Biol. 22, 867-873.

Aghajari, N., Feller, G., Gerday, C., Haser, R., 2002. Structural basis of $\alpha$-amylase activation by chloride. Protein Sci. 6.

André, G., Tran, V., 2004. Putative implication of $\alpha$-amylase loop 7 in the mechanism of substrate binding and reaction products release. Biopolymers 75, 95-108.

Araki, H., Inomata, N., Yamazaki, T., 2001. Molecular evolution of duplicated amylase gene regions in Drosophila melanogaster: evidence of positive selection in the coding regions and selective constraints in the cis-regulatory regions. Genetics 157, 667-677.

Bandani, A.R., Kazzazi, M., Mehrabadi, M., 2009. Purification and characterization of midgut $\alpha$-amylases of Eurygaster integriceps. Entomol. Sci. 12, 25-32.

Bernfeld, P., 1955. Amylases, alpha and beta. Methods Enzymol. 1, 149-158.

Brayer, G.D., Luo, Y., Withers, S.G., 1995. The structure of human pancreatic $\alpha-$ amylase at $1.8 \AA$ A resolution and comparisons with related enzymes. Protein Sci. 4. 1730-1742.

Buonocore, V., Poerio, E., Silano, V., Tomasi, M., 1976. Physical and catalytic properties of $\alpha$-amylase from Tenebrio molitor L. larvae. Biochem. J. 153, 621-625.

Cipolla, A., Delbrassine, F., Da Lage, J.-L., Feller, G., 2012. Temperature adaptations in psychrophilic, mesophilic and thermophilic chloride-dependent $\alpha$-amylases. Biochimie 94 (9), 1943-1950.

Commin, C., Aumont-Nicaise, M., Claisse, G., Feller, G., Da Lage, J.-L., 2013. Enzymatic characterization of recombinant $\alpha$-amylase in the Drosophila melanogaster 
species subgroup: is there an effect of specialization on digestive enzyme? Genes Genet. Syst. 88, 251-259.

D'Amico, S., Gerday, C., Feller, G., 2000. Structural similarities and evolutionary relationships in chloride-dependent $\alpha$-amylases. Gene 253, 95-105.

Da Lage, J.-L., Binder, M., Hua-Van, A., Janecek, S., Casane, D., 2013. Gene make-up: rapid and massive intron gains after horizontal transfer of a bacterial $\alpha$-amylase gene to Basidiomycetes. BMC Evol. Biol. 13, 40.

Da Lage, J.-L., Danchin, E.G.J., Casane, D., 2007a. Where do animal $\alpha$-amylases come from? an interkingdom trip. FEBS Lett. 581, 3927-3935.

Da Lage, J.-L., Kergoat, G.J., Maczkowiak, F., Silvain, J.-F., Cariou, M.-L., Lachaise, D., 2007b. A phylogeny of Drosophilidae using the Amyrel gene: questioning the Drosophila melanogaster species group boundaries. J. Zool. Sys. Evol. Res. 45, 47-63.

Da Lage, J.-L., Renard, E., Chartois, F., Lemeunier, F., Cariou, M.L., 1998. Amyrel, a paralogous gene of the amylase gene family in Drosophila melanogaster and the Sophophora subgenus. Proc. Natl. Acad. Sci. U. S. A. 95, 6848-6853.

Da Lage, J.-L., van Wormhoudt, A., Cariou, M.-L., 2002. Diversity and evolution of the $\alpha$-amylase genes in Animals. Biol. Bratisl. 57, 181-189.

Doane, W.W., 1969. Drosophila amylases and problems in cellular differentiation. In: Hanly, E.W. (Ed.), Problems in Biology : RNA in Development. University of Utah Press, Salt Lake City, pp. 73-109.

Dojnov, B., Božic, N., Nenadović, V., Ivanović, J., Vujčić, Z., 2008. Purification and properties of midgut $\alpha$-amylase isolated from Morimus funereus (Coleoptera: Cerambycidae) larvae. Comp. Biochem. Physiol. B Biochem. Mol. Biol. 149, 153-160.

Feller, G., Le Bussy, O., Houssier, C., Gerday, C., 1996. Structural and functional aspects of chloride binding to Alteromonas haloplanctis $\alpha$-amylase. J. Biol. Chem. 271, 23836-23841.

Hoorn, A.J.W., Scharloo, W., 1978. The functional significance of amylase polymorphism in Drosophila melanogaster. V. The effect of food components on amylase and alpha-glucosidase activity. Genetica 49, 181-187.

Janeček, Š., 1994. Sequence similarities and evolutionary relationships of microbial, plant and animal $\alpha$-amylases. Eur. J. Biochem. 224, 519-524.

Kariya, M., Shigemi, Y., Yano, M., Konno, H., Takii, Y., 2003. Purification and properties of $\alpha$-amylase from Aspergillus oryzae MIBA316. J. Biol. Macromol. 3 57-60.

Kluh, I., Horn, M., Hyblova, J., Hubert, J., Doleckova-Maresova, L., Voburka, Z Kudlikova, I., Kocourek, F., Mares, M., 2005. Inhibitory specificity and insecticidal selectivity of $\alpha$-amylase inhibitor from Phaseolus vulgaris. Phytochemistry 66, 31-39.

Kotkar, H.M., Sarate, P.., Tamhane, V.A., Gupta, V.S., Giri, A.P., 2009. Responses of midgut amylases of Helicoverpa armigera to feeding on various host plants. J. Insect Physiol. 55, 663-670.

Legrand, D., Tenaillon, M., Matyot, P., Gerlach, J., Lachaise, D., Cariou, M.-L., 2009. Species-wide genetic variation and demographic history of Drosophila sechellia, a species lacking population structure. Genetics 182, 1197-1206.

Levitzki, A., Steer, M.L., 1974. The allosteric activation of mammalian $\alpha$-amylase by chloride. Eur. J. Biochem. 41, 171-180.

MacGregor, A.W., 1978. A-amylase I from malted barley--physical properties and action pattern on amylose. Cereal Chem. 55, 754-765.
Maczkowiak, F., Da Lage, J.-L., 2006. Origin and evolution of the Amyrel gene in the $\alpha$-amylase family of Diptera. Genetica 128, 145-158.

Maurus, R., Begum, A., Kuo, H.-H., Racaza, A., Numao, S., Andersen, C., Tams, J.W., Vind, J., Overall, C.M., Withers, S.G., Brayer, G.D., 2005. Structural and mechanistic studies of chloride induced activation of human pancreatic $\alpha$-amylase. Protein Sci. 14, 743-755.

Milanovic, M., Andjelkovic, M., 1992. Adaptive significance of amylase polymorphism in Drosophila - VI. Properties of two amylase variants and the effect of food components on amylase activity in Drosophila subobscura. Comp. Biochem. Physiol. 101B, 611-616.

Nagaraju, J., Abraham, E.G., 1995. Purification and characterization of digestive amylase from the tasar silkworm, Antheraea mylitta (Lepidoptera: Saturnidae). Comp. Biochem. Physiol. 110B, 201-209.

Numao, S., Maurus, R., Sidhu, G., Wang, Y., Overall, C.M., Brayer, G.D., Withers, S.G., 2002. Probing the role of the chloride ion in the mechanism of human pancreatic $\alpha$-amylase. Biochemistry 41, 215-225.

Prigent, S., Matoub, M., Rouland, C., Cariou, M.-L., 1998. Metabolic evolution in $\alpha-$ amylases from Drosophila virilis and D. repleta, two species with different ecological niches. Comp. Biochem. Physiol. 119B, 407-412.

Pytelková, J., Hubert, J., Lepsík, M., Sobotník, J., Sindelka, R., Krízková, I., Horn, M. Mares, M., 2009. Digestive $\alpha$-amylases of the flour moth Ephestia kuehniella -adaptation to alkaline environment and plant inhibitors. FEBS J. 276, $3531-3546$

Qian, M., Ajandouz, E.H., Payan, F., Nahoum, V., 2005. Molecular basis of the effects of chloride ion on the acid-base catalyst in the mechanism of pancreatic $\alpha$ amylase. Biochemistry 44, 3194-3201.

Ramasubbu, N., Ragunath, C., Mishra, P.J., 2003. Probing the role of a mobile loop in substrate binding and enzyme activity of human salivary amylase. J. Mol. Biol. 325, 1061-1076

Shibata, H., Yamazaki, T., 1994. A comparative study of the enzymological features of $\alpha$-amylase in the Drosophila melanogaster species subgroup. Jpn. J. Genet. 69, $251-258$.

Stam, M.R., Danchin, E.G.J., Rancurel, C., Coutinho, P.M., Henrissat, B., 2006. Dividing the large glycoside hydrolase family 13 into subfamilies: towards improved functional annotations of $\alpha$-amylase-related proteins. Prot. Eng. Des. Sel. 19, $555-562$.

Valencia-Jiménez, A., Arboleda, J.W., Lopez Avila, A., Grossi-de-Sà, M.F. 2008. Digestive $\alpha$-amylases from Tecia solanivora larvae (Lepidoptera: Gelechiidae): response to $\mathrm{pH}$, temperature and plant amylase inhibitors. Bull. Entomol. Res. 98, 575-579.

Welker, N.E., Campbell, L.L., 1967. Comparison of the $\alpha$-amylase of Bacillus subtilis and Bacillus amyloliquefaciens. J. Bacteriol. 94, 1131-1135.

Yassin, A., Araripe, L.O., Capy, P., Da Lage, J.-L., Klaczko, L.B., Maisonhaute, C., Ogereau, D., David, J.R., 2008. Grafting the molecular phylogenetic tree with morphological branches to reconstruct the evolutionary history of the genus Zaprionus (Diptera : Drosophilidae). Mol. Phylogenet. Evol. 47, 903-915.

Yezdani, E., Sendi, J.J., Zibaee, A., Ghadamyari, M., 2010. Enzymatic properties of aamylase in the midgut and the salivary glands of mulberry moth, Glyphodes pyloalis Walker (Lepidoptera: Pyralidae). C. R. Biol. 333, 17-22. 